\title{
3 Research Square

\section{Pregnancy and Parenting Experiences of Women With Twin-to-twin Transfusion Syndrome: A Qualitative Study}

\section{Lijie Ren}

Shengjing Hospital of China Medical University

\section{Cancan Song}

Shengjing Hospital of China Medical University

Chunling Xia

Shengjing Hospital of China Medical University

Nan Wang

Shengjing Hospital of China Medical University

Yan Yang

Shengjing Hospital of China Medical University

Shaowei Yin ( $D$ yinshaowei8403@163.com)

Shengjing Hospital of China Medical University https://orcid.org/0000-0002-9635-6364

\section{Research article}

Keywords: twin-to-twin transfusion syndrome, pregnancy and parenting experience, mental state, qualitative research

Posted Date: November 19th, 2020

DOl: https://doi.org/10.21203/rs.3.rs-108770/v1

License: (9) This work is licensed under a Creative Commons Attribution 4.0 International License. Read Full License 


\section{Abstract}

\section{Background}

Qualitative research can reflect the actual thoughts and experience of research subjects and can be used to explore the experiences of women presenting with twin-to-twin transfusion syndrome (TTTS) to facilitate the provision of targeted psychological support.

\section{Methods}

A semi-structured interview method was used to assess the pregnancy and parenting experiences of women who presented with TTTS.

Results

Women who presented with TTTS during pregnancy experienced persistent worry about their children's health from the disease diagnosis to the subsequent parenting processes, when slight changes in their children's health elicited concern. The lack of an efficient referral process and health information increased their uncertainty about their children's health.

\section{Conclusion}

In addition to the children's health, other difficulties encountered during pregnancy and parenting may aggravate the pressure. Regardless of whether with successful delivery, women who experiencing TTTS may be more susceptible to psychological problems. Clinicians should improve the referral process and establish a follow-up system to provide women with health information and psychological support.

\section{Background}

Twin-to-twin transfusion syndrome (TTTS) is a serious complication of monochorionic diamniotic (MCDA) pregnancy. Without timely treatment, the perinatal mortality rate can reach $80-100 \%$. ${ }^{1,2}$ The survival rate of both twins after foetoscopic surgery is low, and the incidence of short-term and long-term neurological complications in surviving children is relatively high. ${ }^{3-5}$ Based on the characteristics of the disease and current treatment status, women with TTTS pregnancies may experience serious adverse events such as loss of the foetus, extremely premature delivery, and poor foetal prognosis. Previous studies have indicated that women with TTTS pregnancies may experience anxiety, depression, posttraumatic stress, and higher parenting pressure, thereby necessitating urgent clinical attention for their mental state. ${ }^{6-9}$ However, based on current research, the lived experiences and actual thoughts during pregnancy and postpartum cannot be definitively determined, which precludes adequate the provision of targeted treatments. In this regard, qualitative research is a method used to describe the life experiences of research subjects, capturing their emotions, beliefs, and behaviours. Under a framework of patientcentred care, qualitative research has received extensive attention from clinical professionals. ${ }^{10-12}$ Our 
study utilized a semi-structured interview method to explore the experiences of pregnancy and parenting as well as the main difficulties encountered by women with TTTS, so as to develop possible solutions for improving the mental state of these women in the pre- and post-partum periods.

\section{Methods}

\section{Participants, Ethics, and Eligibility}

This study was conducted in a foetal medicine centre of China. The hospital database was searched for patients diagnosed with TTTS from January 2018 to December 2019. Ethical approval was obtained from the ethics committee of Affiliated Shengjing Hospital of China Medical University on 18 January 2018. The study was conducted according to the principles of the Declaration of Helsinki. We contacted patients by telephone, explained the purpose of the study in detail, and invited them to participate in the study. Specific interview times were confirmed with participants. All the women participating in this research received an informed consent form in electronic version, we started the interview after ensuring that they understood the content of the informed consent form and obtained their electronic signature. And we informed them that we may quote our conversations in research results, but we would conceal the information that could identify them. In research results,all quotations we used obtained participants' agreement. Heterogeneity was noted among participants, including difference in treatment decisions and outcomes, methods of conception, and pregnancy history. ${ }^{13}$

\section{Data collection}

A semi-structured interview method was used for data collection. Participants close to the foetal medicine centre attended face-to-face interviews. Participants from other cities were interviewed by telephone. All interviews were recorded with the consent of the participants. To ensure the objectivity and truthfulness of the data, we learned and practiced the methods and skills of interviews and data analysis. ${ }^{14,15}$ The interviews were conducted according to the following three themes: their experience following a diagnosis of TTTS, parenting experience after childbirth, and main problems encountered and help required from the time of diagnosis to the parenting period. The specific questions are presented in Supplementary file 1(English language version and the Chinese language version).

\section{Data analysis}

We transcribed the recorded data within 24 hours and noted the emotional state of the interviewee, including laughing, crying, pauses, and silence. After the transcription, another researcher assessed the recordings and text. The Colaizzi method was used for data analysis ${ }^{11}$ : two researchers read the text data repeatedly, extracted and coded statements related to the research purpose, and handled the different codes. The meaning of the coding was then summarised, the theme was refined, and the process of forming the theme in detail was written out for verification by a third researcher. The results were then returned to the interviewee to verify the authenticity of the content. ${ }^{15}$ 


\section{Results}

\section{Demographics}

During the study period, a total of 62 women were diagnosed with TTTS in our hospital, and 18 of them participated in the study with the age range of 24 to 39 . Of participants, six attended face-to-face interviews, and 12 underwent telephone interviews. Of the patients, 15 received foetoscopy treatment, and three refused treatment. The average age of the interviewee's survivors was 14 months.Interviewees' pregnancy history and pregnancy outcomes are shown in Table 1.

Table 1 Pregnancy history and basic information of interviewees 


\begin{tabular}{|c|c|c|c|c|c|}
\hline interviewees & $\begin{array}{l}\text { conception } \\
\text { method }\end{array}$ & $\begin{array}{l}\text { number of } \\
\text { Surviving } \\
\text { children }\end{array}$ & $\begin{array}{l}\text { number of } \\
\text { adverse } \\
\text { pregnancy }\end{array}$ & $\begin{array}{l}\text { whether } \\
\text { referral }\end{array}$ & $\begin{array}{l}\text { interview time } \\
\text { to delivery } \\
\text { or miscarriage }\end{array}$ \\
\hline $\mathrm{A} 1$ & $\begin{array}{l}\text { Assisted } \\
\text { reproduction }\end{array}$ & 2 & 1 & No & 11months \\
\hline A2 & $\begin{array}{l}\text { Natural } \\
\text { conception }\end{array}$ & 2 & 0 & No & 12 months \\
\hline A3 & $\begin{array}{l}\text { Natural } \\
\text { conception }\end{array}$ & 2 & 2 & Yes & 8 months \\
\hline A4 & $\begin{array}{l}\text { Natural } \\
\text { conception }\end{array}$ & 2 & 0 & No & 16 months \\
\hline A5 & $\begin{array}{l}\text { Natural } \\
\text { conception }\end{array}$ & 1 & 0 & No & 18 months \\
\hline A6 & $\begin{array}{l}\text { Natural } \\
\text { conception }\end{array}$ & 2 & 0 & Yes & 12 months \\
\hline A7 & $\begin{array}{l}\text { Natural } \\
\text { conception }\end{array}$ & 1 & 1 & Yes & 13 months \\
\hline A8 & $\begin{array}{l}\text { Natural } \\
\text { conception }\end{array}$ & 2 & 1 & Yes & 12 months \\
\hline A9 & $\begin{array}{l}\text { Assisted } \\
\text { reproduction }\end{array}$ & 1 & 2 & Yes & 8 months \\
\hline A10 & $\begin{array}{l}\text { Assisted } \\
\text { reproduction }\end{array}$ & 0 & 3 & Yes & 8months \\
\hline A11 & $\begin{array}{l}\text { Natural } \\
\text { conception }\end{array}$ & 2 & 0 & No & 9 months \\
\hline A12 & $\begin{array}{l}\text { Natural } \\
\text { conception }\end{array}$ & 0 & 1 & Yes & 10 months \\
\hline A13 & $\begin{array}{l}\text { Natural } \\
\text { conception }\end{array}$ & 1 & 0 & No & 19 months \\
\hline A14 & $\begin{array}{l}\text { Natural } \\
\text { conception }\end{array}$ & 1 & 1 & No & 20 months \\
\hline A15 & $\begin{array}{l}\text { Assisted } \\
\text { reproduction }\end{array}$ & 2 & 2 & Yes & 23 months \\
\hline A16 & $\begin{array}{l}\text { Natural } \\
\text { conception }\end{array}$ & Refuse surgery & 0 & Yes & 20 months \\
\hline A17 & $\begin{array}{l}\text { Natural } \\
\text { conception }\end{array}$ & Refuse surgery & 0 & Yes & 19 months \\
\hline A18 & $\begin{array}{l}\text { Natural } \\
\text { conception }\end{array}$ & Refuse surgery & 1 & No & 12 months \\
\hline
\end{tabular}




\section{Themes}

After coding and analysing the text data, three themes emerged: (1) the experiences and emotions in different periods, (2)the main barriers encountered from diagnosis to parenting,(3) required support.

\section{The experiences and emotion in different periods}

\section{Diagnosis experience:}

MCDA is a high-risk pregnancy that receives more attention from clinicians than a normal single pregnancy. Although patients may be informed of potential risks from previous pregnancies, the joy of having twins was the primary mood of early pregnancy in the absence of abnormal foetal indicators. The shock, sadness, and extreme worry about foetal health experienced by patients at the time of TTTS diagnosis showed a considerable contrast with the joy experienced in the previous period. "The early indicators of foetuses were very normal. When the doctor told me the TTTS, I was shocked and wondered how could this happen to me? It was the first time I heard about this disease, and I thought it was very serious, I was very scared and worried that both foetuses were dead".

\section{Treatment decision experience}

As foetoscopy is currently the preferred treatment method, the choice of treatment method did not concern the patients. The main issue they faced was whether to accept surgery, and family support was a critical factor in their decision. For women who opted for surgery, their primary concern was to save the foetuses. These patients believed that it was fortunate for them to have the opportunity for treatment. "We know the risks and prognosis of the operation, but no matter what the outcome was, we must have the operation. As long as there was a glimmer of hope, we must give the child a chance; then, we would have no regrets". For women who refused treatment, the decision-making process was extremely painful. After considering the potential risks, they had to decide on giving up the foetuses. Such patients typically had good fertility or already had offspring but lacked the support of family members, especially the support of their husbands. "During pregnancy, I accompanied their growth and I was very reluctant to give up my children. But I had no other choice and I could not decide on this matter alone. My family did not support me for treatment, they said that I must be responsible for my other children, and I could get pregnant again easily. We all could not accept unhealthy children".

\section{Postoperative pregnancy experience}

Frequent monitoring is required after treatment, as patients had to bear the pressure of potential risks such as premature delivery, intrauterine death, and foetal short-term and long-term complications; further, they faced the stimulation of sudden changes in foetal health. Many women stated that their uncertainty and worry about foetal health lasted from diagnosis to delivery. When the foetuses were in their womb, the pressure induced by foetal health had to be borne almost entirely by themselves. 
"Surgery did not relax me too much. I was afraid that the foetuses were born too early and had sequelae. I always felt uneasy at home, because I could not see or touch them, and I did not know their state. I did not dare to move around after returning home". "My family always comforted me, but I felt it did not work, I had to digest the pressure by myself'.

The survival rate of both twins after foetoscopy is not ideal, and some women may face the risk of losing a foetus. The previous success of the operation provided hope, and the sudden loss of a foetus created a substantial psychological gap for patients, leading the women to worry about the other foetus. In women who lost both foetuses concurrently, the heavy blow implied that their previous efforts were in vain."I was very happy that the two foetal condition had improved at the beginning of the examination, but in the next examination, the doctor said that the small foetus had died. I really couldn't accept it at that time, and my mood suddenly went from heaven to hell. Although I knew that the small foetus health was not good, I still did not want to lose him, and I have been worried about whether there would be problems with the big one".

"It was really a pity that the two twins all died, I was so proud of this gestation. All my effort for the foetuses was in vain. I did not know how to face it. I didn't want to do and think anything at that time".

\section{Mother-infant separation experience}

The successful birth of the foetuses ended with the mother bearing most of the stress. However, the hospitalisation of the children led to another type of pressure. During this period, they were worried about their children's health and experienced self-blame for not accompanying their children. "It was all my fault. The children suffered so much from birth, I didn't fulfil my responsibility as a mother". "I was crazy, I could not sleep, I could not do other things, and my heart was fully occupied by the children. I wanted to know everything about the children, I took the phone and waited for the hospital to contact me, but I was worried about bad news coming from the phone. If the children had a complication, I would not be able to survive."

\section{Heavy parenting pressure}

Accompanying the children throughout their growth was a positive experience overall, but for women experiencing TTTS, they also faced greater parenting pressure. These pressures mainly arose from the economic burden caused by the disease and the more serious concern for the children's health in the parenting process. Due to the occurrence of TTTS in the gestation, regardless of whether the children had been hospitalised after birth, these mothers said that they could not take care of them like normal children. They were highly vigilant about their children's health and were sensitised to any small abnormalities. They would pay special attention to the children's development at each time point. If the children did not complete a milestone at a specific time, they would become anxious and look for ways to promote the child's growth." When the children were just discharged, I was worried that they would suddenly stop breathing. Looking after them was like a job. We made sure that someone was caring for them all the time, especially at night. I did not dare to sleep". "Almost every month there were things that 
worried me, such as when he should look up, sit up, and stand up. If they developed later than children of the same age, I would be anxious. I would take them to the hospital and give them various dietary supplements. I would try anything to promote their growth".

Raising children who were diagnosed with a developmental disorder was even more troubling. They blamed themselves for bringing the children into this world, only to experience tribulation. Daily rehabilitation therapies slowly wore away their patience, and the uncertainty about the outcome of their children's rehabilitation made them feel hopeless, but the love for children made them unable to give up easily. "It was all my fault, and I became more and more suspicious of the original decision. If I had given up treatment at the beginning, the children would not suffer so much pain. Sometimes it was very annoying, why the denouement was bad after I put in so much effort. But after all, they are my own children, and I could not give up".

\section{Long-term grief}

Losing a foetus was excruciatingly painful for women experiencing TTTS. Whether they lost two foetuses after the operation or chose to give up treatment, they would blame themselves for foetal death, and selfblame and guilt persisted for a long time after the pregnancy. "I often had nightmares. I was sorry for my children and that I was unable to save them". For women who lost one foetus, they would often think of the lost foetus in the stage of raising the surviving child and loved the surviving child more passionately. "When I see the surviving child, I often think that I once had twins, but only one survived. I felt regretful every time I thought about it. Now, I can only give more love to the living child".

\section{Main barriers}

\section{Lack of information at the foetal medicine centre}

The treatment of TTTS was centred in the foetal medicine centre, and most patients required a referral. However, there is currently no referral process specifically for women with TTTS. Most first-visit doctors only informed them of the name of the foetal medicine centre, and patients were required to search for information about the foetal medicine centre and the referral process on their own. A substantial period of time may have been wasted in this process. Most patients thought that the process from the first-visit hospital to the foetal medicine centre was the most convoluted. They worried that the foetuses would suddenly die on the way to the centre or due to a lack of timely treatment. "After discovering the abnormality, we drove over at night. The stress was the greatest on the way, and I cried all the way. We did not know the situation of foetal medicine centre, we did not know how to find the doctor for treatment, whether the hospital would accept me, or whether there was a chance for treatment. We were afraid that the foetuses would die on the way".

\section{Unable to distinguish authenticity of information}

As the treatment for TTTS was centred in the foetal medical centre, it was difficult for women who experienced TTTS to obtain timely information and support from the treatment hospital and first- 
diagnostic hospitals during pregnancy and parenting. The Internet became the main method for them to obtain health information. However, information on the Internet was complicated, and it was difficult for them to determine the authenticity of the information without professional guidance. "I always search information from the Internet, but I did not know whether I should trust the information I found. Sometimes there were two completely different results, and I did not know which one to trust. In order to avoid sadness, I would choose to trust the positive information".

\section{Too much worry}

Women receiving treatment would pay particular attention to foetal examination indicators and their own physiological changes after surgery. For example, after obtaining colour Doppler ultrasound results, they would compare the blood flow and amniotic fluid values with normal results. After being discharged from the hospital, they would be extremely concerned about possible contractions. Any abnormality would increase their anxiety. They knew that their worry was unnecessary and affected their lives, but no one told them what they should pay attention to. "After the operation, I was very worried about everything about the foetus. For example, I would be anxious when I had contractions, and when there were changes in foetal movement, but I felt that the doctor did not care about these like I did. Was my worry unnecessary? I had always been afraid that the foetuses would be affected". The situation was the same after birth. Developmental status, lack of trace elements, and changes in the number of bowel movements would all catch their attention. They were also aware that their anxiety might have affected their children, but due to the TTTS experience, they could not help paying attention to these details. "I knew every detail of the children's development. At every development point I would see whether my children had reached the standard milestones. If they did not meet the standard, I would become anxious".

\section{The help needed}

During pregnancy and parenting process, the biggest stress source for women with TTTS experience was the children's health. We cannot easily change the health status of children, but there were things that could be done more easily that were of great help to improve their mental state throughout the whole process

\section{More optimised referral process}

Due to the lack of information on the disease, during this referral process,patients were full of fear of losing the foetuses. They hoped that the first-visit doctor could explain the basic facts of the disease, treatment status, and possibility of foetal complications during the referral. Access to reliable information could reduce the women's anxiety and prevent blind-searching for disease information. In addition, the first-visit hospital should establish a closer relationship with the foetal medicine centre and inform patients of the treatment and referral process to help them find the treating doctor in time and alleviate their worries about treatment timing and availability. "I hoped that the doctor would not just tell me the name of the foetal medicine centre, they could tell me how the disease would develop next. Would the 
foetuses die on my way to the foetal medicine centre? Would the foetal condition worsen quickly? His words determined my mentality during the referral". "I hoped the first doctor could tell me what to do at the foetal medicine centre to find the treating doctor in time, instead of searching the treatment hospital and blindly relying on myself."

\section{Professional guidance}

Patients would encounter significant confusion in the process of postoperative pregnancy and later parenting. They hoped to contact the practitioners at the foetal medicine centre to obtain professional advice when encountering problems. Any form of contact, such as telephone, WeChat, or an Official Account, would provided excellent psychological support for them. "Every time I encountered a problem, I hoped that a professional could tell me what to do. If they told me not to worry, then I would really not worry about it...especially if I trusted the professionals".

\section{Psychological support}

TTTS women described their lives as a level-breaking game. From discovering the disease to parenting process, they had to go through many checkpoints. The doctor's attention and comfort during the hospital stay was crucial psychological support. After discharge from the hospital, communication with other women with TTTS with better pregnancy outcomes could significantly reduce their psychological pressure. "I hoped that the doctors and nurses could pay more attention to me, be willing to discuss the children's situation with me and answer the confusion in my heart. This would have made me feel more relieved". "I especially hoped that I could discuss the children's situation with women who had TTTS experience, so that we would provide great psychological support to each other".

\section{Discussion}

We found that the emotional reactions during pregnancy of women experiencing TTTS varied and their uncertainty about the children's health persisted from diagnosis to the postpartum parenting process. Due to the influence of TTTS during pregnancy, regardless of whether the children were hospitalised after birth, these women faced greater parenting pressure after birth. The lack of health information aggravated their uncertainty about the children's health, and small abnormalities would cause them to be alert and anxious. For women who lost their children, their thoughts, guilt, and sadness for the dead children persisted for a long time. In addition, we observed that optimising the referral process, ensuring more convenient access to reliable information, and providing peer support could alleviate their pregnancy and parenting pressure.

Women who miscarried due to various reasons faced negative emotions such as post-traumatic stress and sadness for a long time after delivery.${ }^{16,17}$ For women experiencing preterm birth, in addition to the negative emotional reactions mentioned above, they worried about the children's health and faced high parenting pressure. ${ }^{18,19}$ Our study identified that women who encountered miscarriage or preterm birth because of TTTS would had more complex emotions. During pregnancy, in addition to surgery, they also 
dealt with the fluctuation in foetal health, and their mood was calm only after a successful birth. As their children's health was affected by both TTTS and premature birth, their parenting pressure was greater than that of women who experienced preterm birth because of other reason. Considering the complicated pregnancy and parenting experiences of such women, clinicians should pay attention to their psychological problems, especially women who lost foetuses because of TTTS or had poor fertility. The results of this study suggest that helping women to establish good peer support and to contact more TTTS women with good pregnancy outcome was a way to improve their mental state.

In addition, optimising the referral process and providing them with healthcare guidance and reliable knowledge would reduce their psychological pressure. Previous studies have shown that women who were transferred for treatment due to premature birth had uncertainty about the foetal outcome and difficulties in adapting to the new hospital environment. ${ }^{20}$ Our study demonstrated that due to the lack of specialised referral channels, the most significant difficulty experienced by TTTS patients was that they were required to find information about the foetal medicine centre by themselves. Due to the lack of health information from the first-diagnosing hospital, they were full of fear of the disease and uncertainty about treatment opportunities during the referral process. An efficient referral process would ensure that patients received timely treatment and get relief from anxiety during the waiting period. ${ }^{21,} 22$ Therefore, regional hospitals and foetal medicine centres should establish closer relationships, establish direct medical channels to help patients who need intrauterine treatment to find a treating doctor quickly. Before the referral, the first-diagnosing doctor should inform the patients of the characteristics of TTTS and possible disease-associated changes during the referral in order to alleviate their worry about foetal death. However, for women who experienced TTTS, merely providing information support when the disease was diagnosed was insufficient to meet the patients' needs. Women had a high demand for foetal health information during pregnancy. ${ }^{23,24}$ For women who experience serious medical events during pregnancy, continuous disease information and psychological support should be provided to reduce the risk of subsequent mental illness. ${ }^{25,26}$ Our study observed that due to cross-regional treatment, women with TTTS had difficulty obtaining postpartum healthcare information from foetal medical centres, and it was difficult for local hospitals to provide precise advice. The lack of information caused them to be at a loss when they dealt with children's health problems. In order to provide patients with more information, the foetal medicine centre should communicate relevant disease information with the first-diagnosing hospital to improve the information education of first-diagnosing hospital. Before patients are discharged from the foetal medicine centre, the hospital should provide sufficient disease information, so that the patient will be capable of coping with disease-associated changes. In addition, the foetal medicine centre should establish a long-term follow-up system to provide a convenient way for women with TTTS experience to contact the foetal medicine centre to address their problems.

\section{Advantages and disadvantages}

This study utilised a semi-structured interview to explore the pregnancy and parenting experience of women with TTTS. Our results could reflect their true feelings from the diagnosis of the disease to the parenting process. However, given that patients resided in other regions, most interviews were conducted 
by telephone, and we could not accurately identify the emotional state of the interviewees. In addition, due to the small number of participants experiencing miscarriage, the research results may not fully reflect the pregnancy and postpartum life experience of these patients.

\section{Conclusion}

Women who experienced TTTS and successfully gave birth faced great psychological pressure during pregnancy and the postpartum period due to children's health problems. Clinicians should improve the referral process and establish a follow-up system to provide such women with health information support to improve their mental state. For women who miscarried due to TTTS, their sadness and longing for the lost foetuses persisted for a long time. These patients are a high-risk population for mental illness, and more clinical attention should be provided to these women. Future studies can explore follow-up strategies for such people and intervention methods to improve their mental state.

\section{Abbreviations}

TTTS: Twin-to-twin transfusion syndrome

MCDA:Monochorionic diamniotic

\section{Declarations}

\section{Details of ethics approval}

Ethical approval was obtained from the ethics committee of Affiliated Shengjing Hospital of China Medical University (2018PS20K) on 18 January 2018. The study was conducted according to the principles of the Declaration of Helsinki.

\section{Consent for publication and Authors' contributions}

LJ R:I declare that I participated in the design, data collection and analysis, and the writing of the paper. I have seen and approved the final version and that it has neither been published nor submitted elsewhere.

CC S: I declare that I participated in the data analysis and the writing of the paper. I have seen and approved the final version and that it has neither been published nor submitted elsewhere.

CL X: I declare that I participated in data collection and analysis, and the writing of the paper. I have seen and approved the final version and that it has neither been published nor submitted elsewhere.

$\mathrm{N}$ W: I declare that I participated in the data analysis and the writing of the paper. I have seen and approved the final version and that it has neither been published nor submitted elsewhere. 
YY: I declare that I participated in the design ,data analysis and the writing of the paper. I have seen and approved the final version and that it has neither been published nor submitted elsewhere.

SW Y: I declare that I participated in the design ,data collection and analysis, and the writing of the paper. I have seen and approved the final version and that it has neither been published nor submitted elsewhere.

\section{Funding}

This work was supported by the National Key Research \&Department Program of China,No.2018YFC1002902. The fund mainly finances interviewees' expense because of the research and the expense of polishing and publishing article.

Competing Interests:There is none Interests

Availability of data and materials:Not applicable

\section{Acknowledgements}

We thank all the team members who participated in the research. We are particularly grateful to the women who participated in our study,they dedicated their precious time and willing to share their experiences,so our research can complete smoothly.

\section{References}

1 Marwan Al, Zaretsky M, Feltis B. Complex multigestational anomalies. Seminars in pediatric surgery 2019;28(4).

2 Robyr R, Lewi L, Salomon LJ, Yamamoto M, Bernard JP, Deprest J, et al. Prevalence and management of late fetal complications following successful selective laser coagulation of chorionic plate anastomoses in twin-to-twin transfusion syndrome. American journal of obstetrics and gynecology 2006;194(3):796-803.

3 Korsakissok M, Groussolles M, Dicky O, Alberge C, Casper C, Azogui-Assouline C. Mortality, morbidity and 2-years neurodevelopmental prognosis of twin to twin transfusion syndrome after fetoscopic laser therapy: a prospective, 58 patients cohort study. Journal of gynecology obstetrics and human reproduction 2018;47(10):555-560.

4 Murgano D, Khalil A, Prefumo F, Mieghem TV, Rizzo G, Heyborne KD, et al. Outcome of twin-to-twin transfusion syndrome in monochorionic monoamniotic twin pregnancy: systematic review and metaanalysis. Ultrasound in obstetrics \& gynecology : the official journal of the International Society of Ultrasound in Obstetrics and Gynecology 2020;55(3):310-317. 
5 Spruijt M. S,Lopriore E,Tan R,Slaghekke F,Klumper, F,Middeldorp J.M et al. Long-Term Neurodevelopmental Outcome in Twin-to-Twin Transfusion Syndrome: Is there still Room for Improvement? Journal of clinical medicine 2019;8(8).

6 Edwards DM,Gray PH,Soong B,Chan FY,Cincotta R. Parenting stress and psychosocial health in mothers with twin-twin transfusion syndrome managed with laser surgery: a preliminary study. Twin Research and Human Genetics 2007;10(2):416-421.

7 Schifsky K, Deavenport-Saman A, Mamey MR, Sheth N, Mirzaian CB, Schrager SM, et al. Risk Factors for Parenting Stress in Parents of Children Treated with Laser Surgery for Twin-Twin Transfusion Syndrome 2 Years Postpartum. American journal of perinatology 2020.

8 Falletta L, Fischbein R, Bhamidipalli S, Nicholas L. Depression, anxiety, and mental health service experiences of women with a twin-twin transfusion syndrome pregnancy. Arch Womens Ment Health 2018;21(1):75-83.

9 Vergote S, Lewi L, Gheysen W, De Catte L, Devlieger R, Deprest J. Subsequent fertility, pregnancy, and gynecologic outcomes after fetoscopic laser therapy for twin-twin transfusion syndrome compared with normal monochorionic twin gestations. American journal of obstetrics and gynecology 2018;218(4):441447.

10 Nelson PA. Getting under the skin: qualitative methods in dermatology research. The British journal of dermatology 2015;172(4):841-843.

11 Pauling JD, Domsic RT, Saketkoo LA, Almeida C, Withey J, Jay H, et al. Multinational Qualitative Research Study Exploring the Patient Experience of Raynaud's Phenomenon in Systemic Sclerosis. Arthritis care \& research 2018;70(9):1373-1384.

12 Tong A, Winkelmayer W, Craig JJAjokdtojotNKF. Qualitative research in CKD: an overview of methods and applications. Am J Kidney Dis 2014;64(3):338-346.

13 Moser A, Korstjens I. Series: Practical guidance to qualitative research. Part 3: Sampling, data collection and analysis. European Journal of General Practice 2018;24(1):9-18.

14 McGrath C, Palmgren P, Liljedahl M. Twelve tips for conducting qualitative research interviews. Medical Teacher 2019;41(9):1002-1006.

15 Korstjens I, Moser A. Series: Practical guidance to qualitative research. Part 4: Trustworthiness and publishing. European Journal of General Practice 2018;24(1):120-124.

16 Pitt P, McClaren BJ, Hodgson J. Embodied experiences of prenatal diagnosis of fetal abnormality and pregnancy termination. Reproductive health matters 2016;24(47):168-177. 
17 Côté-Arsenault D, Denney-Koelsch E. "Have no regrets:" Parents' experiences and developmental tasks in pregnancy with a lethal fetal diagnosis. Social science \& medicine (1982) 2016;154:100-109.

18 Beck CT, Harrison L. Posttraumatic Stress in Mothers Related to Giving Birth Prematurely: A Mixed Research Synthesis. Journal of the American Psychiatric Nurses Association 2017;23(4):241-257.

19 Yaari M, Treyvaud K, Lee KJ, Doyle LW, Anderson PJ. Preterm Birth and Maternal Mental Health: Longitudinal Trajectories and Predictors. Journal of pediatric psychology 2019;44(6):736-747.

$20 \mathrm{~L} . \mathrm{W}, \mathrm{J} . \mathrm{G}, . \mathrm{HD}$. The stories of women who are transferred due to threat of preterm birth. Women and birth : journal of the Australian College of Midwives 2018;31(4):307-312.

21 Neimanis I, Gaebel K, Dickson R, Levy R, Goebel C, Zizzo A, et al. Referral processes and wait times in primary care. Canadian family physician Medecin de famille canadien 2017;63(8):619-624.

22 Wong J, Tu K, Bernatsky S, Jaakkimainen L, Thorne JC, Ahluwalia V, et al. Quality and continuity of information between primary care physicians and rheumatologists. BMC rheumatology 2019.

23 Ghiasi A. Health information needs, sources of information, and barriers to accessing health information among pregnant women: a systematic review of research. The journal of maternal-fetal \& neonatal medicine, 2019:1-11.

24 Wexler A, Davoudi A, Weissenbacher D, Choi R, O'Connor K, Cummings H, et al. Pregnancy and health in the age of the Internet: A content analysis of online "birth club" forums. PloS one 2020;15(4).

25 Furniss M, Conroy M, Filoche S, MacDonald EJ, Geller SE, Lawton B. Information, support, and followup offered to women who experienced severe maternal morbidity. International journal of gynaecology and obstetrics,2018;141(3):384-388.

26 Wall-Wieler E, Carmichael SL, Urquia ML, Liu C, Hjern A. Severe maternal morbidity and postpartum mental health-related outcomes in Sweden: a population-based matched-cohort study. Arch Womens Ment Health 2019;22(4):519-526.

\section{Supplementary Files}

This is a list of supplementary files associated with this preprint. Click to download.

- Supplementaryfile1.docx

- Supplementaryfile1.docx 